\title{
Research on Upgrading Path of China's Equipment Manufacturing Industry under Carbon Tax Policy
}

\author{
Zhongmin Ma \\ Management School \\ Xuzhou Institute of Technology \\ Xuzhou, China
}

\author{
Qianqian Wen \\ Management School \\ Xuzhou Institute of Technology \\ Xuzhou, China
}

\begin{abstract}
Carbon tax has been recognized internationally as an important measure to control greenhouse gases to promote energy conservation and emission reduction with the increasing carbon emissions. The equipment manufacturing industry, viewed as the heart of industry and the pillar industry of the national economy, is the foundation of carbon tax, and the ultimate payer of carbon tax. It is analyzed in this paper that how to effectively deal with the carbon tax making a sustainable development at the key moment when the equipment manufacturing industry is changing and upgrading in the background of supply side reformation, discussing the opportunities and challenges of equipment manufacturing industry under implementation of carbon tax policy, providing a upgrading path of equipment manufacturing industry under carbon tax background.
\end{abstract}

Keywords-carbon tax; equipment manufacturing industry; high-end

\section{INTRODUCTION}

The carbon tax is a policy coping with carbon dioxide emissions established by governments to reduce carbon emissions and protect environment[1], which also compensates for the deficiency of tax system on energy and environment protection of China. According to "Report on Development of Chinese Equipment Manufacturing Industry", the item of "equipment manufacturing industry" covers all enterprises manufacturing machinery, electronics, bio-products etc., is the generic terms for all the national economy and the national safety technical equipment enterprises, is the foundation of national economic development especially industrial development[2]. The equipment manufacturing industry of China is big but weak, with high energy consumption and low technical content, labor costs improve. There are new challenges because of the implementation of carbon tax faced by the equipment manufacturing industry of China under the global competition background of "Industry 4.0 strategy" provided by German Government in 2013, "Chinese manufacturing 2025" published by China in 2015, and the 13th Five-Year Plan promoting the development of high-end equipment manufacturing industry. It is necessary to study the upgrading path of equipment manufacturing industry under the carbon tax policy, in order to achieve sustainable and healthy

Fund project: Projects of the National Social Science Foundation of China, NO. 15BGL144; Excellent Projects of Social Science Application Research of Jiangsu Province, NO. 16SYC-016; Projects of College Philosophy and Social Science Foundation in Jiangsu Province, NO.2016SJD790029, NO.2016SJD630086 development and enhance the international competitiveness.

\section{The Problems EXISTING In DEVELOPMENT OF EQUIPMENT MANUFACTURING INDUSTRY OF CHINA}

\section{A. Lack of Independent Innovation Ability, and Dependency of Core Technology on Import}

Although China has become the largest country of manufacturing equipment in the word, lack of independent innovation capacity, depending on import for core technology, and less independent knowledge products, result in low valueadded products [3]. As showed in statistics that in China equipment manufacturing industry, Chinese enterprises only obtain meager income, $40 \%$ of integrated circuit chip manufacturing equipments, $80 \%$ of large petrochemical equipment manufacturing equipments, $70 \%$ of key manufacturing equipments for car and high-end intensive equipment still depend on importing. Affected by traditional economy development, most enterprises pursue short-term economic benefits, take less investment in research and development, produce low-end and low value-added products, and obtain the profit mainly relying on cheap labor and low cost [4]. And now the low cost advantage of equipment manufacturing industry of China has been losing, at the same times many foreign enterprises have been transferring to Southeast Asia, compared with the developed countries, the international competitiveness of equipment manufacturing industry in China is still weak.

\section{B. Large Energy Consumption, Serious Environmental Pollution}

Throughout the developments of the United States, Germany and Japan, their economic development and international status are based on the development of equipment manufacturing industry. The equipment manufacturing industry has an important strategic position in economic development, which consumes smaller resource in manufacturing process, but the products manufactured by it consumed more energy, accounted for $2 / 3$ of total energy consumption. The equipment manufacturing industry has been the extensive mode with low resource utilization, and large consumption of resources and energy, at the same time, China's energy structure is more coal and oil, but less clean 
energy, which leads to a large number of waste emissions and serious environmental problems in China.

\section{The Structure of Equipment Manufacturing Industry Is Irrational with Less High-End Equipment Manufacturing Industries}

Equipment manufacturing industry is the base of industrial power, and the material basis of social and economic development. After Reform and Opening-up, the equipment manufacturing industry of China has been effectively promoted under rapid economic growth, of which structure is irrational and lack of high-end equipment manufacturing industries. Since high-end equipment manufacturing industry will require the enterprises to invest a lot of manpower, material and financial resources to research technology and new products, these initial requirements of high cost, high risk and long-term payback, result in the condition of less high-end equipment manufacturing industries, while the number of medium and low products are accounted for the most with weak international competitiveness and less "low-carbon" equipments that have independent intellectual property rights.

\section{Lack of High-End Equipment and Technical Personnel}

Equipment manufacturing industry is a technology intensive industry, of which technology innovation relies on a large number of high technology talents. But there are not much more low carbon talents in China, and poor professional education started late, coupled with poor management of China's equipment manufacturing industry that is lack of incentive policies for technical personnel and inadequate investment in scientific research, so as that the personnel couldn't meet the development of equipment manufacturing industry, which have been restricting the low carbon technology innovation of equipment manufacturing industry enterprises.

\section{OPPORTUNITIES AND CHALLENGES OF EQUIPMENT MANUFACTURING INDUSTRY UNDER CARBON TAX POLICY}

\section{A. Challenges}

First, the implementation of carbon tax policy has increased the cost of equipment manufacturing industry, and reduced profits. Since the equipment manufacturing industry is the main consumer of energy resources in China, is the main payer of carbon tax, at the same time, it is facing a critical moment of transformation and upgrading, carbon tax will undoubtedly give a heavy blow to the equipment manufacturing industry, which may lead to shrinking of high polluting enterprises, and even a overall reduction of whole industry if they fail to find the right way [5]. Secondly, the implementation of carbon tax will weaken the competitiveness of China's equipment manufacturing industry, especially international competitiveness. As we know, the equipment manufacturing industry of China, and even the whole manufacturing industry, occupies a large foreign market because of the low cost which will be increased by the carbon tax, thus affecting the competitiveness of enterprises.

\section{B. Opportunities}

1) Improve energy efficiency: The carbon tax will increase the cost of the equipment manufacturing industry of which enterprises will try to make reduction of carbon emissions which reduce carbon emissions carbon emissions which relies on improving energy efficiency using new technology to reduce production costs and increase profits. Therefore, the carbon tax will promote the improvement of energy efficiency and energy-saving technology.

2) Accelerate to close down outdated production facilities, promote transformation and upgrading of the industry: Carbon tax is bound to accelerate to close down outdated production facilities of the equipment manufacturing industry of which enterprises need to actively seek new energy, new technology, which will promote the emergence and development of a new equipment manufacturing industry with environmental protection and energy-saving, so as to change the mode of high energy consumption, low value-added, high pollution, promote the transformation and upgrading of the equipment manufacturing industry. Therefore, the implementation of carbon tax policy will promote the transformation and upgrading of the whole industry.

3) Enhancing the competitiveness of the equipment manufacturing industry, and increasing added-value of products: With the implementation of carbon tax, enterprises are trying to reduce costs by improving energy efficiency, and developing energy-saving technology in order to form a economic development mode with low pollution, low energy consumption and low cost, so as to improve the competitiveness of equipment manufacturing industry.

In conclusion, the opportunity and challenge can be summarized as follows: in a short term, the carbon tax will indeed give a certain pressure on the equipment manufacturing industry [6]; while in a long term, there is an important significance because of the implementation of carbon tax on development of the equipment manufacturing industry and even the whole economy of China. But opportunities are more than challenges, the national strategy of "China Manufacturing $2025^{\prime \prime}$ and the 13th Five-Year Plan have been laid a very important external environment for the equipment manufacturing industry of China.

\section{THE UPGRADING PATH OF CHINESE EQUIPMENT MANUFACTURING INDUSTRY UNDER THE CARBON TAX POLICY}

\section{A. Form An Effective Technical Innovation System to Achieve High-End Intelligent Manufacturing}

Equipment manufacturing industry is a typical technology intensive industry which can maintain competitive advantage only through technological breakthrough innovation. The structure of equipment manufacturing industry must be upgraded in reformation of supply-side in order to improve technology level and form independent innovation; actively introduce foreign advanced technology, and insist on innovating during digestion and absorption; strengthen the cooperation of production, education and research, integrated innovation, high-end intelligent manufacturing, and low 
energy consumption in order to achieve sustainable innovation. Through the coordination of key laboratories, enterprise technology centers, and engineering research centers by government, an effective technology innovation system will be established, through increasing fund to support core technology, key technology, in order to develop waste treatment technology and reduce innovation cost and promote the transformation of high-end manufacturing equipment industry.

\section{B. Improve Resource Utilization Efficiency, Achieve Low- Carbon Manufacturing and Change Energy Utilization Mode}

There is a base path to reduce energy consumption and total carbon emission that improving the efficiency of resource utilization, so as to achieve low-carbon manufacturing and change the mode of energy utilization. The carbon tax will increase the cost of manufacturing equipment manufacturing enterprises, which requires enterprises to continuously improve the efficiency of resource utilization, maximize using clean energy, develop alternative resources to reduce using coal resources, carry out waste recycle and green production mode. Also we can learn foreign enterprises have low-carbon production experience, combined with the actual situation of China, to seek an effective way solving the problem of energy utilization. Continuously adjust industries structure of the equipment manufacturing industry, actively develop high value-added products, at the same time develop some low value-added products as an assist so as to broaden enterprises profits; develop high-end equipment manufacturing industry to close down outdated production facilities, promote harmonious development of the equipment manufacturing industry; promote the green environmental protection equipment manufacturing industries so as to improve the competitiveness of products.

\section{Developing the Enterprise Culture of Low Carbon, Cultivating Top Talents}

Since the influence of culture on enterprise is subtle, invisible, and durable, especially in establishment of talent team, the enterprise culture will be used to enhance the trust between enterprises and employees so as to achieve double win, improve employee loyalty, and prevent a loss of talent; developing low-carbon culture and forming the awareness of energy-saving and emission reduction, which will influence everyone of the enterprise with low carbon culture to improve business level and produce low carbon products, so as to extend low carbon culture into everywhere in the enterprise.

A lot of talents are needed by technology development and innovation, which are formed by cooperation of production, education and research. Enterprises need to increase intelligence investment, combined with talent utilization benefit, and should make flexible incentive policies to attract talent from abroad, attract and retain top talent. The cooperation of production, education and research has a significant impact on promoting national economic construction and social development, which is indispensable for cultivation of low-carbon talent.

\section{Perfect Law and Regulation, and Strengthen Low-Carbon Equipments Support}

Although the carbon tax policy has promoted low-carbon technological innovation, but since the equipment manufacturing industry is technology intensive, the risks and costs involved in innovation are bound to be high. Especially compared with developed countries, the equipment manufacturing industry of China is still lack of low carbon technology, so as to invest more and face more risk, which need supporting of laws, policies, and fund from government, so as to support low carbon technology innovation of equipment manufacturing enterprises. Actively learn from Britain and the United States, Japan, Europe and other foreign countries' experience to develop and improve the low carbon comprehensive laws and regulations, and concrete operation standard procedure to promote low-carbon technology innovation of enterprises, protect, certificate and promote low carbon achievements timely; make financial policy for low carbon technology innovation, timely take incentive policies, perfect low carbon environmental protection equipment procurement system of government to form guiding and demonstration effect of procurement.

\section{CONCLUSION}

The Equipment manufacturing industry has an important strategic position in economic development of China, but is large rather than strong. In order to change the current status of high energy consumption and high pollution, the equipment manufacturing industry of China should go ahead. The carbon tax will bring new opportunities and challenges for the equipment manufacturing industry which will achieve sustainable and healthy development through technological innovation, low carbon manufacturing, talents cultivating and perfecting laws.

\section{REFERENCES}

[1] Ni Juan. Analysis on Carbon Tax and Carbon Emissions Trading Mechanism [J]. Taxation Research, 2016, (04): 46-50.

[2] Liu Zunfeng, Zhao Shuang, Zhang Chunling. Study on the Promoting Innovation Ability of Equipment Manufacturing Industry in Low Carbon Economy - A Case Study of Tangshan, Hebei [J]. Ecological Economy, 2013, (10): 163-165.

[3] Cai Ruilin. Research on the Path of Low-Cost Innovation Driving HighEnd Manufacturing Industry [J] .Science research, 2014, (03): 384-399.

[4] Zhang Danning. Research on the Development Level and Mode of China's Equipment Manufacturing Industry [J]. Quantitative Economic Technology Research, 2014, (7): 99-114.

[5] Li Jinrong. The Urgency and Countermeasures of Levying Environmental Tax in China [J] .Pricing Theory \& Practice, 2015, (02): 97-299.

[6] Han Xueli. Study on the Carbon Tax in Response to Climate Change [J]. Reform and Strategy, 2014, (12): 55-97 